\title{
Clinical Utility of CYP2C19 Genotype-Guided Antiplatelet Therapy in Patients at Risk of Adverse Cardiovascular and Cerebrovascular Events: A Review of Emerging Evidence
}

This article was published in the following Dove Press journal:

Pharmacogenomics and Personalized Medicine

\author{
Megan N Gower' \\ Lindsay R Ratner' \\ Alexis K Williams (D)' \\ Joseph S Rossi ${ }^{2}$ \\ George A Stouffer $\mathbb{D}^{2,3}$ \\ Craig R Lee $\mathbb{D}^{1,3}$ \\ 'Division of Pharmacotherapy and \\ Experimental Therapeutics, UNC \\ Eshelman School of Pharmacy, Chapel \\ Hill, NC, USA; ${ }^{2}$ Division of Cardiology, \\ UNC School of Medicine, Chapel Hill, \\ NC, USA; ${ }^{3}$ UNC McAllister Heart \\ Institute, University of North Carolina at \\ Chapel Hill, Chapel Hill, NC, USA
}

Correspondence: Craig R Lee

Tel + I 919-843-7673

Email craig_lee@unc.edu

\begin{abstract}
In patients undergoing percutaneous coronary intervention (PCI), the standard of care is dual antiplatelet therapy with a $\mathrm{P}_{2} \mathrm{Y}_{12}$ inhibitor (clopidogrel, prasugrel, or ticagrelor) and aspirin. Current clinical practice guidelines now recommend more potent $\mathrm{P} 2 \mathrm{Y}_{12}$ inhibitors (prasugrel or ticagrelor) over clopidogrel in acute coronary syndrome (ACS). However, clopidogrel remains the most commonly prescribed $\mathrm{P}_{2} \mathrm{Y}_{12}$ inhibitor in the setting of PCI and is also the preferred agent in the treatment and secondary prevention of stroke. Clopidogrel is a prodrug that requires bioactivation by the CYP2C19 enzyme. It has been shown that clopidogrel use in patients who are CYP2C19 no function allele carriers are associated with impaired antiplatelet inhibition and a higher risk of major adverse cardiovascular and cerebrovascular events. Compared to clopidogrel, prasugrel and ticagrelor clinical response is not impacted by CYP2C19 genotype. Even with a demonstrated increased risk of adverse outcomes in CYP2C19 no function allele carriers treated with clopidogrel, routine implementation of CYP2C19 genotyping to guide antiplatelet therapy selection has remained controversial and has not been widely adopted. Recent results from multiple prospective randomized and nonrandomized clinical trials investigating the use of CYP2C19 genotypeguided antiplatelet therapy following PCI have advanced the evidence base demonstrating the clinical utility of this strategy. Multiple recent studies have examined the effects of CYP2C19 genotype on clopidogrel outcomes in the setting of stroke and neurointerventional procedures. In this review, we discern the clinical utility of using CYP2C19 genotype testing to guide antiplatelet therapy prescribing by evaluating the impact of CYP2C19 genotypeguided selection of antiplatelet therapy on clinical outcomes, summarizing emerging data from cardiovascular and neurology clinical studies, and discussing implications for clinical practice guidelines, remaining knowledge gaps and future research directions.
\end{abstract}

Keywords: percutaneous coronary intervention, clopidogrel, CYP2C19, precision medicine, pharmacogenetics, stroke

\section{Introduction}

Approximately 600,000 percutaneous coronary interventions (PCI) are performed in the United States (US) each year. ${ }^{1}$ To prevent major adverse cardiovascular events (MACE) such as death, stent thrombosis, myocardial infarction (MI), and stroke following PCI, dual antiplatelet therapy consisting of aspirin and a $\mathrm{P} 2 \mathrm{Y}_{12}$ inhibitor (clopidogrel, prasugrel or ticagrelor) remains the standard of care. ${ }^{2}$ 
Although clinical practice guidelines now recommend prasugrel and ticagrelor over clopidogrel in acute coronary syndrome (ACS) patients undergoing PCI, clopidogrel remains the most widely prescribed $\mathrm{P}_{2} \mathrm{Y}_{12}$ inhibitor and the only agent indicated following elective PCI., ${ }^{2,3}$

Clopidogrel is a prodrug that requires bioactivation by the cytochrome P450 (CYP) 2C19 enzyme. It is well-established that patients carrying CYP2C19 no function alleles have an impaired capacity to convert clopidogrel to its active metabolite and inhibit platelet aggregation. ${ }^{4}$ As a consequence, CYP2C19 no function allele carriers treated with clopidogrel exhibit a significantly higher risk of MACE post-PCI, ${ }^{5}$ and recurrent stroke after an acute ischemic stroke or transient ischemic attack (TIA), ${ }^{6}$ compared to clopidogrel-treated patients without a CYP2C19 no function allele. In contrast, CYP2C19 no function alleles do not impact the pharmacokinetics, antiplatelet effects, or clinical effectiveness of prasugrel or ticagrelor. ${ }^{7,8}$ Although accumulating evidence has demonstrated that utilization of CYP2C19 genotype-guided antiplatelet therapy after PCI improves clinical outcomes, ${ }^{9,10}$ and some centers have implemented CYP2C19 genotyping into clinical workflows, ${ }^{11}$ the clinical utility of this precision medicine strategy has remained controversial and has not been widely adopted.

In this review, we evaluate the impact of CYP2C19 genotype-guided selection of antiplatelet therapy on clinical outcomes, summarize emerging data from recent cardiovascular and neurology clinical trials and registries, and assess how these recently published data may impact clinical practice guidelines. We also discuss remaining knowledge gaps and future research directions that should be addressed to discern the clinical utility of using CYP2C19 genotype testing to guide antiplatelet therapy prescribing in clinical practice.

\section{CYP2CI9 Genotype and Metabolizer Phenotypes}

It is well-documented that substantial interpatient variability in CYP2C19 metabolism can be largely attributed to genetic polymorphisms in CYP2C19. ${ }^{12,13}$ Three alleles account for the majority of $\mathrm{CYP} 2 \mathrm{C} 19$ genetic variation across populations: $\mathrm{CYP} 2 \mathrm{C} 19 * 2, * 3$ and $* 17 . \mathrm{CYP} 2 \mathrm{C} 19 * 2$ and CYP2C19*3 are no function alleles that yield a metabolically inactive CYP2C19 protein. CYP2C19*2 (rs4244285, c. $681 \mathrm{G}>\mathrm{A}$ ) changes the splice site at the intron 4/exon 5 junction, prematurely terminates protein translation, and has a minor allele frequency (MAF) of approximately
$12-15 \%, 15-18 \%$, and $25-30 \%$ in European, African, and Asian populations, respectively. ${ }^{4,12-14}$ CYP2C19*3 (rs4986893, c.636G $>$ A) creates a premature stop codon in exon 4 (W212X). The MAF is $<1 \%$ in European and African populations, and approximately $5 \%$ in Asian populations. Other rare no function alleles include CYP2C19*4, *5, *6, $* 7$ and $* 8$ (MAF $<0.5 \%$ in all studied populations). ${ }^{4}$ CYP2C19*17 (rs12248560, $-806 \mathrm{C}>\mathrm{T}$ ) is an increased function allele that increases $\mathrm{CYP} 2 \mathrm{C} 19$ transcription and CYP2C19 enzyme expression. ${ }^{4}$ The MAF is approximately $20 \%$ in European and Black populations, and 5\% in Asian populations. ${ }^{4,12,13}$

As defined by the Clinical Pharmacogenomics Implementation Consortium (CPIC), and summarized in Figure 1, combinations of no function and increased function alleles make up five distinct phenotypes: ultrarapid metabolizer (UM), rapid metabolizer (RM), normal metabolizer (NM), intermediate metabolizer (IM), and poor metabolizer (PM). ${ }^{15}$ Approximately $30 \%$ of White populations, $35 \%$ of Black populations, and $60 \%$ of East Asian populations are CYP2C19 IMs or PMs. ${ }^{4,13}$ Approximately $30 \%$ of White and Black populations, and 3\% of East Asian populations are CYP2C19 RMs or UMs.

\section{CYP2CI9 Pharmacogenomics and $\mathrm{P} \mathrm{Y}_{12}$ Inhibitor Pharmacology}

Clopidogrel is a thienopyridine prodrug that requires hepatic biotransformation by CYP enzymes to an active metabolite, which irreversibly inhibits the adenosine diphosphate (ADP) $\mathrm{P}_{2} \mathrm{Y}_{12}$ receptor (Figure 2A). Approximately $85 \%$ of absorbed clopidogrel is hydrolyzed by carboxylesterase-1 (CES1) into an inactive metabolite. The remaining $15 \%$ is available for bioactivation by CYP2C19 and other CYP isoforms in humans.

CYP2C19 IMs and PMs treated with clopidogrel have significantly lower active metabolite plasma concentrations and diminished inhibition of platelet activation and aggregation compared to NMs. ${ }^{4}$ Multiple retrospective studies have shown that CYP2C19 IMs and PMs exhibit a significantly higher risk of MACE after PCI compared to those without a no function allele. ${ }^{5,7,8}$ Some retrospective studies have reported that individuals carrying one or two CYP2C19*17 increased function alleles exhibit increased active metabolite formation, increased inhibition of platelet aggregation, increased bleeding risk, and decreased MACE risk with clopidogrel. ${ }^{16-18}$ However, other studies have reported no association between CYP2C19 RM or UM status and 


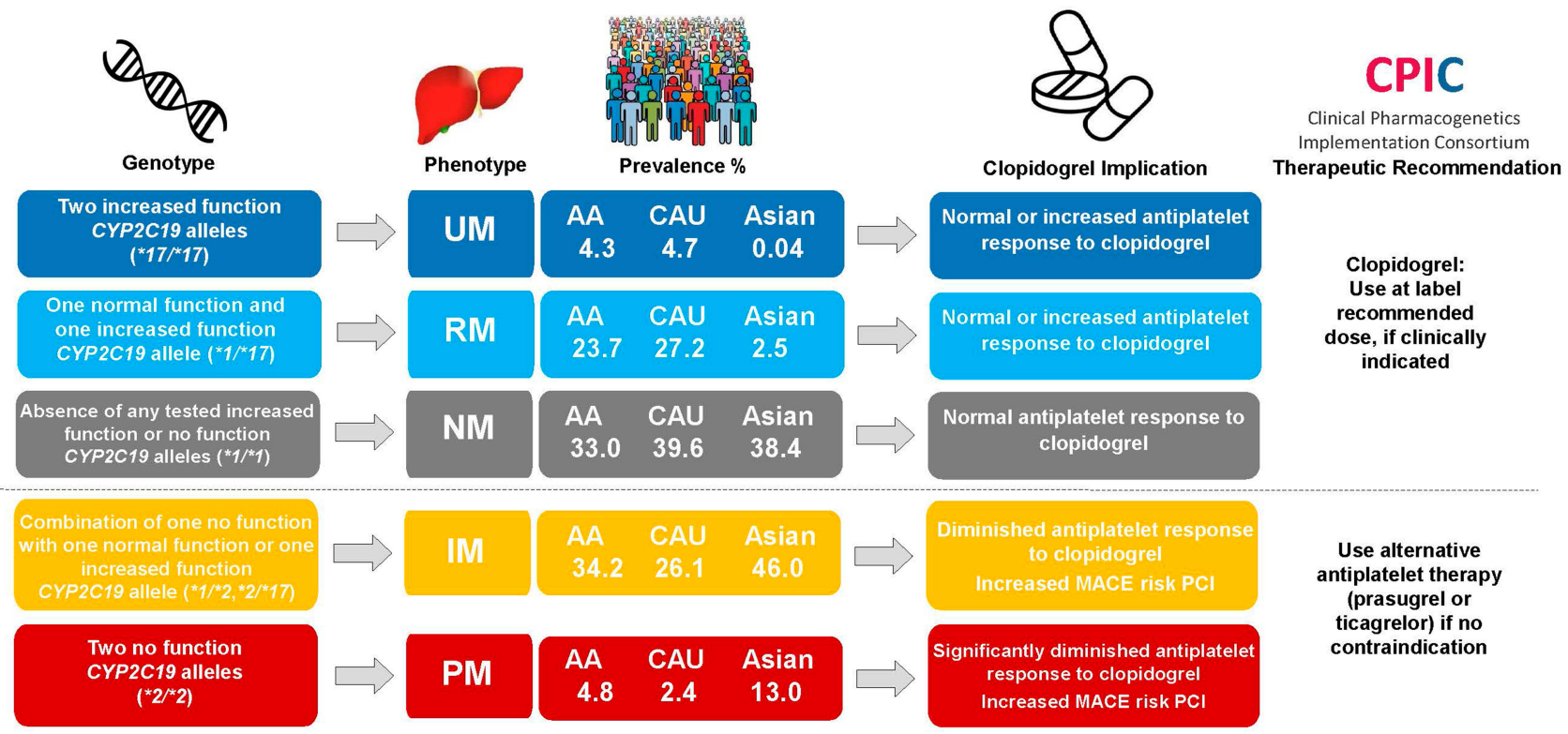

Figure I CYP2C19 metabolizer phenotypes, response to clopidogrel, and therapeutic recommendations. Clopidogrel genotype, metabolizer phenotype, estimated population frequency in Caucasians (European), African-Americans and Asian (East Asian), and implications and therapeutic recommendations for clopidogrel according to the Clinical Pharmacogenomics Implementation Consortium guidelines. 4,15 Patients with one nonfunctional and one increased function allele (eg, CYP2CI9* $/ * 17$ diplotype) are classified as intermediate metabolizers. Metabolizer phenotype prevalence was estimated using minor allele frequencies provided in the CPIC CYP2CI 9 Frequency Table ${ }^{4}$ and Hardy-Weinberg calculations.

Abbreviations: AA, African-American; CAU, Caucasian; IM, intermediate metabolizer; NM, normal metabolizer; PM, poor metabolizer; RM, rapid metabolizer; UM, ultrarapid metabolizer.

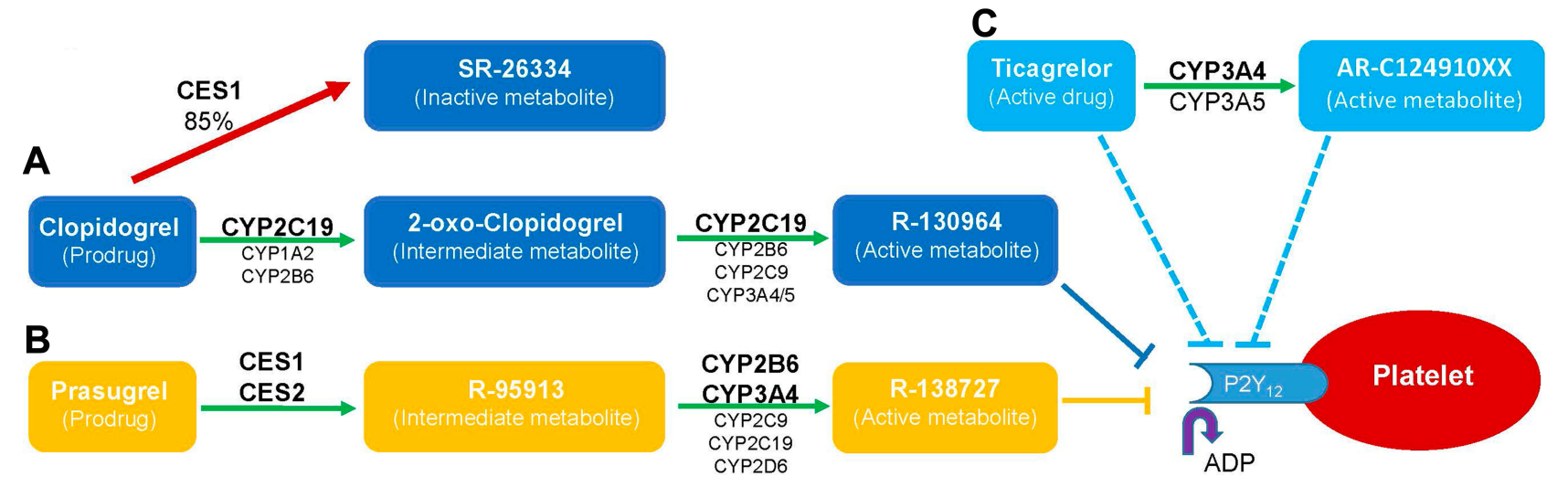

Figure 2 Overview of $\mathrm{P}_{2} \mathrm{Y}_{12}$ Inhibitor Pharmacology. (A) Clopidogrel: Approximately $85 \%$ of clopidogrel is hydrolyzed by carboxylesterase-I (CESI) into an inactive metabolite (SR-26,334). The remaining 15\% is subject to a two-step metabolic activation in the liver. CYP2CI9 and to a lesser extent by CYPIA2 and CYP2B6, form an intermediate metabolite (2-oxo-clopidogrel). 2-oxo-clopidogrel is hydrolyzed by CESI to the inactive acid metabolite or oxidated by CYP2CI9, with lesser contributions by others CYPs, to the active thiol metabolite (R-130,964). The active metabolite covalently binds the P2Y 12 subunit of platelet ADP receptors to irreversibly inhibit ADPmediated platelet activation and aggregation. (B) Prasugrel is rapidly hydrolyzed in the intestine by carboxylesterase-2 (CES2), and subsequently in the liver by CESI, to form a thiolactone intermediate metabolite (R-95,9/3). R-95,913 is metabolized by CYP3A4 and CYP2B6, with lesser contributions by CYP2C19 and other CYPs to an active metabolite (R-138,727) that is an irreversible P2Y 12 inhibitor. (C) Ticagrelor is metabolized by CYP3A4, and to a lesser extent CYP3A5, to produce its active metabolite $(A R-C I 24910 X X)$. Both ticagrelor and $A R-C 124910 X X$ are equipotent, direct-acting, reversible, noncompetitive $P 2 Y_{12}$ inhibitors that act at a distinct site on the $P 2 Y_{12}$ receptor to prevent ADP-mediated platelet activation.

clopidogrel pharmacodynamics and clinical outcomes. ${ }^{19,20}$ Therefore, the clinical implications of the CYP2C19*17 allele on clopidogrel clinical effectiveness remain unclear. ${ }^{4}$

Prasugrel is also a thienopyridine prodrug. In contrast to clopidogrel, prasugrel undergoes bioactivation by CYP3A4, CYP2B6 and to a lesser extent CYP2C19 (Figure 2B). ${ }^{7}$
Ticagrelor is a cyclopentyl-triazolopyrimidine that inhibits the $\mathrm{P}_{2} \mathrm{Y}_{12}$ receptor in a reversible, noncompetitive manner (Figure 2C). ${ }^{8}$ Ticagrelor is metabolized by CYP3A4 into an active metabolite that has equipotent antiplatelet effects as the parent drug. Overall, prasugrel and ticagrelor exhibit more consistent antiplatelet effects compared to clopidogrel. 
The pharmacokinetics, antiplatelet effects, and clinical effectiveness of prasugrel and ticagrelor are unaffected by CYP2C19 alleles. Post-hoc genetic analyses of the PLATO and TRITON-TIMI clinical trials demonstrated that CYP2C19 genotype has no effect on cardiovascular outcomes after PCI in patients randomized to ticagrelor or prasugrel. ${ }^{7,8}$ Moreover, these analyses demonstrated that the reduction in MACE conferred by ticagrelor and prasugrel compared to clopidogrel were driven in large part by the increased risk of MACE in CYP2C19 IMs and PMs randomized to clopidogrel. ${ }^{7,8,21}$ Although ticagrelor pharmacokinetics and antiplatelet effects have been associated with genetic variants in CYP3A4, SLCO1B1, and UGT2B7, these effects were relatively modest and did not impact ticagrelor effectiveness or safety outcomes. ${ }^{22,23}$ Genetic variants associated with the antiplatelet and clinical effects of prasugrel have not been identified to date.

\section{Current Guideline}

\section{Recommendations for Genotype- Guided Antiplatelet Therapy After PCI}

The association between CYP2C19 no function alleles, clopidogrel clinical pharmacology, and diminished clopidogrel clinical effectiveness is reflected in clopidogrel's prescribing information. In 2010, the US Food and Drug Administration (FDA) added a Boxed Warning to the clopidogrel label that recommended against the use of clopidogrel in CYP2C19 PMs after PCI. ${ }^{24}$ This warning was extended to include all clopidogrel indications in a 2017 FDA safety communication due to the availability of alternative therapies (eg, prasugrel or ticagrelor), if clinically indicated. ${ }^{25}$ However, the FDA warning does not mandate CYP2C19 genetic testing in patients prescribed clopidogrel.

Clinical practice guidelines vary regarding recommendations for CYP2C19 genetic testing. CPIC offers recommendations for pharmacogenomic-based prescribing under the assumption that the genetic test results are already available. ${ }^{4}$ The CPIC guidelines for clopidogrel (last updated in 2013) recommend the use of alternative therapy (prasugrel or ticagrelor) in CYP2C19 IMs or PMs without a contraindication to alternative therapy (Figure 1). Due to the accumulation of prospective outcomes data, a CPIC guideline update is currently in development. Consistent with CPIC, the Dutch Pharmacogenetics Working Group (DPWG) guideline (most recently updated in 2018) recommends the use of alternative antiplatelet therapy in CYP2C19 IMs and PMs. The DPWG also suggests that doubling the clopidogrel maintenance dose to $150 \mathrm{mg} /$ day (following a $600 \mathrm{mg}$ loading dose) may be considered in CYP2C19 IMs. ${ }^{26}$

The American College of Cardiology Foundation, American Heart Association, and the Society for Cardiovascular Angiography and Interventions (ACCF/ AHA/SCAI) PCI guideline recommends that CYP2C19 genetic testing, with use of prasugrel or ticagrelor in CYP2C19 IMs and PMs, may be considered in patients undergoing PCI who are at high risk of poor outcome due to inadequate platelet inhibition (Class IIB, Level of Evidence C). ${ }^{27}$ However, the guidelines recommend against routine CYP2C19 genetic testing in all PCI patients due to lack of clearly demonstrated clinical utility. ${ }^{2,27}$ Recent European Society of Cardiology (ESC) guidelines do not make recommendations regarding CYP2C19 genotyping. ${ }^{28,29}$ Additionally, a 2019 expert consensus statement noted that CYP2C19 genotyping may provide useful prognostic data about cardiovascular risk in patients undergoing PCI for ACS; however, routine genotyping to guide escalation to prasugrel or ticagrelor in CYP2C19 no function allele carriers or de-escalation to clopidogrel in patients without a CYP2C19 no function allele is not recommended due to a lack of clinical trials demonstrating the clinical utility of these strategies. ${ }^{30}$

Taken together, current practice guidelines open the door for clinicians to use CYP2C19 genotyping to guide antiplatelet prescribing decisions after PCI in carefully selected, high-risk patients. However, recommendations against routine use of genetic testing have been driven by a lack of large randomized-controlled clinical trials demonstrating the clinical utility of a genotype-guided strategy.

\section{Clinical Outcomes of Genotype- Guided Antiplatelet Therapy After PCI}

A series of recent prospective studies have advanced the evidence base supporting the use of CYP2C19 genotypeguided antiplatelet therapy in clinical practice. ${ }^{9,10}$ Multiple prospective studies investigated the impact on platelet reactivity as a surrogate measure of clinical outcomes. ${ }^{31-}$ ${ }^{34}$ A recent pragmatic, randomized trial of CYP2C19 genotyping implementation demonstrated that return of genetic test results influenced antiplatelet therapy prescribing after PCI. ${ }^{35}$ In addition, multiple nonrandomized ${ }^{36,38}$ 
and randomized trials ${ }^{39,41}$ have examined the impact of genotype-guided-antiplatelet therapy on clinical outcomes. Collectively, these studies demonstrate that a genotypeguided strategy, whereby prasugrel or ticagrelor are prescribed in CYP2C19 IM and PMs, lowers the risk for high on-treatment platelet reactivity and MACE compared to conventional treatment strategies, without significantly increasing bleeding risk.

\section{Nonrandomized Studies}

Several recent observational and pragmatic trials have investigated the impact of CYP2C19 genotype-guided antiplatelet therapy on clinical outcomes in patients undergoing PCI.

\section{International Registries}

In 628 Chinese PCI patients, genotype-guided therapy was associated with a lower risk of MACE at 12 months compared to conventional therapy $(4.2 \%$ vs $9.4 \%$; $\mathrm{p}=0.010$ ), with no difference in bleeding. ${ }^{42}$ Similarly, in 719 Spanish PCI patients, a genotype-guided strategy was associated with a lower risk of MACE (10.1\% vs $14.1 \%$; $\mathrm{p}=0.037$ ) and no difference in bleeding risk compared to historical controls who received conventional therapy. ${ }^{43}$ Lastly, a study of 3260 Dutch patients undergoing elective PCI demonstrated that the use of prasugrel was associated with a lower risk of MACE compared to clopidogrel (5\% vs $31 \%$; $=0.003$ ) in CYP2C19 PMs. $^{44}$

\section{IGNITE Network}

A multisite, pragmatic investigation conducted by seven early adopter US institutions in the Implementing Genomics in Practice (IGNITE) Network examined clinical outcomes of genotype-guided antiplatelet therapy after PCI $(n=1815) .{ }^{36}$ Prasugrel or ticagrelor was recommended in CYP2C19 IMs and PMs, with the ultimate prescribing decision left to the provider. The strategies and challenges encountered at each institution during the initial implementation are detailed in a separate publication. ${ }^{11}$ Prasugrel or ticagrelor was prescribed more often in CYP2C19 IM/PMs compared to patients without a no function allele $(60.5 \%$ vs $15.5 \%$, respectively). CYP2C19 IM/PMs prescribed clopidogrel experienced a significantly higher risk of MACE over 12 months after PCI (defined as death, MI, or ischemic stroke) compared to IM/PMs that received alternative therapy (23.4 vs 8.7 events/100 patient-years; adjusted HR: 2.26 ; $95 \% \mathrm{CI}$ : $1.18-4.32 ; \mathrm{p}=0.013)$. These effects were pronounced in highrisk patients that underwent PCI for an ACS indication (39.0 vs 8.9 events/100 patient-years; adjusted HR: 2.87 ; 95\% CI:
1.35-6.09; $p=0.013)$. Importantly, the observed clinical benefit was driven by IMs, since approximately $90 \%$ of the PMs were treated with alternative therapy.

\section{UNC-Chapel Hill}

A single-center analysis of 1063 patients who underwent PCI and CYP2C19 genotyping at the University of North Carolina at Chapel Hill (572 of which were included in the IGNITE analysis) also demonstrated that clopidogrel use in CYP2C19 IM/PMs was associated with a significantly higher risk of MACE (defined as death, ACS, stent thrombosis, ischemic stroke or TIA) compared to alternative therapy, particularly during the first 30 days after PCI. ${ }^{45,46}$ No difference in clinically significant bleeding events was observed between groups. In addition, IM/PMs initiated and continued on clopidogrel had a significantly higher risk of experiencing either a MACE or bleeding event compared to IM/PMs escalated to prasugrel or ticagrelor (52 vs 19 events/100 patient-years; adjusted HR: 2.89; 95\% CI: 1.44-6.13; $\mathrm{p}=0.003)$. In contrast, patients without a no function allele de-escalated to clopidogrel had no difference in risk compared to patients initiated and continued on prasugrel or ticagrelor (21 vs 19 events/100 patient-years; adjusted HR: 1.13; 95\% CI: $0.51-2.34 ; \mathrm{p}=0.751){ }^{38}$

\section{GIANT}

The Routine CYP2C19 Genotyping to Adjust Thienopyridine Treatment After Primary PCI for STEMI (GIANT) study was a prospective, multicenter, pragmatic study in French STEMI patients undergoing PCI $(n=1445) .{ }^{37}$ CYP2C19 genotype results were used to optimize antiplatelet therapy treatment. Specifically, PMs were recommended to receive prasugrel, IMs were recommended to receive either prasugrel or clopidogrel $150 \mathrm{mg} /$ day, and patients without a no function allele were treated per provider discretion. The primary endpoint was MACE (defined as death, MI, or stent thrombosis) over 12 months. No difference was found between non-IM/PMs prescribed conventional therapy and IM/PMs prescribed intensified antiplatelet therapy $(3.0 \%$ vs $3.3 \%$; HR: $1.10 ; 95 \%$ CI: $0.49-2.44$; $\mathrm{p}=0.82$ ). Notably, approximately $15 \%$ of $\mathrm{IM} / \mathrm{PMs}$ received clopidogrel $75 \mathrm{mg} /$ day, and these individuals had a significantly higher risk of MACE (15.6\%).

\section{Randomized Trials}

Early evidence for the benefit of genotype-guided therapy was demonstrated in a single-site randomized trial of 600 Chinese PCI patients. ${ }^{47}$ In the genotype-guided arm, IMs 
Table I Summary of the POPular Genetics and TAILOR-PCI Clinical Trials

\begin{tabular}{|c|c|c|}
\hline & POPular Genetics & TAILOR-PCI \\
\hline $\mathrm{N}$ & 2488 & 5302 \\
\hline Study population & $\mathrm{PCl} / \mathrm{STEMI}$ & $\mathrm{PCl}$ (ACS or non-ACS indication) \\
\hline Trial design & $\begin{array}{l}\text { Randomized, Open-label } \\
\text { Non-inferiority }\end{array}$ & $\begin{array}{l}\text { Randomized, Open-label } \\
\text { Superiority }\end{array}$ \\
\hline Geographic regions & Netherlands, Belgium, Italy & United States, Canada, Mexico, Korea \\
\hline Sites & 10 sites & 41 sites \\
\hline Primary inclusion criteria & $\begin{array}{l}\text { - Patient }>21 \text { years of age } \\
\text { - Presentation with STEMI } \\
\text { - Primary PCI with stenting }\end{array}$ & $\begin{array}{l}\text { - Patient }>18 \text { years of age } \\
\text { - Presentation with ACS or stable CAD } \\
\text { - Eligible for PCI }\end{array}$ \\
\hline $\begin{array}{l}\text { Standard therapy group } \\
\text { (reference) }\end{array}$ & $\begin{array}{l}\text { Ticagrelor or Prasugrel } \\
\text { (prescriber discretion) }\end{array}$ & Clopidogrel (75 mg/day) \\
\hline Genotype-guided group & $\begin{array}{l}\text { Rapid turnaround } \mathrm{CYP} 2 \mathrm{C} 19 \text { genotyping ( } * 2 \text { and } * 3 \text { allele) } \\
\text { - } \mathrm{CYP} 2 \mathrm{Cl} 19 * 2 \text { or } * 3 \text { carrier: Ticagrelor or prasugrel (prescri- } \\
\text { ber discretion) } \\
\text { - Non-carrier (wild-type): Clopidogrel (de-escalation strategy) }\end{array}$ & $\begin{array}{l}\text { Rapid turnaround CYP2C19 genotyping ( } * 2 \text { and } * 3 \text { allele) } \\
\text { - CYP2C19*2 or } * 3 \text { carrier: Ticagrelor (escalation strategy) } \\
\text { - Non-carrier (wild-type): Clopidogrel }\end{array}$ \\
\hline Primary outcome & $\begin{array}{l}\text { I) Net adverse clinical events defined as: major thrombotic event } \\
\text { (death from any cause, MI, definite stent thrombosis, or stroke) or } \\
\text { PLATO major bleeding event } \\
\text { 2) PLATO major or minor bleeding }\end{array}$ & $\begin{array}{l}\text { Major adverse cardiovascular event (MACE) defined as: CV death, } \\
\text { non-fatal MI, stent thrombosis, non-fatal stroke, or severe } \\
\text { recurrent ischemia }\end{array}$ \\
\hline Follow-up & 12 months & 12 months \\
\hline Primary results & $\begin{array}{l}\text { Net adverse clinical events: } \\
\text { - Genotype-guided group: } 5.1 \% \\
\text { - Standard treatment group: } 5.9 \% \\
\text { - Non-inferiority: absolute difference }-0.7 \%(95 \% \mathrm{Cl}-2.0 \text { to } \\
0.7) \text {; P<0.00। } \\
\text { - Superiority analysis: Hazard ratio } 0.87(95 \% \mathrm{Cl} 0.62 \text { to } \mathrm{I} .2 \mathrm{I}) \text {; } \\
\mathrm{P}=0.40 \\
\text { Primary bleeding outcome: } \\
\text { - Genotype-guided group: } 9.8 \% \\
\text { - Standard treatment group: } 12.5 \% \\
\text { - Superiority analysis: Hazard ratio } 0.78(95 \% \mathrm{Cl} 0.6 \mathrm{I} \text { to } 0.98) \text {; } \\
\text { P=0.04 } \\
\text { Thrombotic outcome (secondary): } \\
\text { - Genotype-guided group: } 2.7 \% \\
\text { - Standard treatment group: } 3.3 \% \\
\text { - Non-inferiority: absolute difference- } 0.3 \%(95 \% \mathrm{Cl}-1.4 \text { to } \\
\text { - Superiority analysis: Hazard ratio } 0.83(95 \% \mathrm{Cl} 0.53 \text { to } 1.3 \mathrm{l})\end{array}$ & $\begin{array}{l}\text { MACE: } \\
\text { - Genotype-guided group ( } \mathrm{n}=903 * 2 \text { or } * 3 \text { carriers who } \\
\text { received ticagrelor): } 4.0 \% \\
\text { - Standard treatment group ( } \mathrm{n}=946 * 2 \text { or } * 3 \text { carriers who } \\
\text { received clopidogrel): } 5.9 \% \\
\text { - Absolute difference: }-1.8 \%(95 \% \mathrm{Cl}-3.9 \text { to } 0.1) \\
\text { - Hazard ratio } 0.66 \text { ( } 95 \% \mathrm{Cl} 0.43 \text { to } 1.02) ; \mathrm{P}=0.056 \\
\text { MACE within } 90 \text { days (post hoc analysis): } \\
\text { - Absolute difference: }-2.1 \%(95 \% \mathrm{Cl}-3.4 \text { to }-1.0) \\
\text { - Hazard ratio } 0.21 ; \mathrm{P}=0.001\end{array}$ \\
\hline Conclusion & $\begin{array}{l}\text { In STEMI patients undergoing } \mathrm{PCl}, \mathrm{CYP} 2 \mathrm{Cl} 9 \text { genotype-guided } \\
\text { selection of } \mathrm{P}_{2} \mathrm{Y}_{12} \text { inhibitor therapy was a safe and effective strategy } \\
\text { compared to standard therapy with ticagrelor or prasugrel. } \\
\text { A genotype-guided strategy was noninferior with respect to } \\
\text { thrombotic events; and significantly decreased bleeding events. }\end{array}$ & $\begin{array}{l}\text { In ACS and non-ACS patients undergoing } \mathrm{PCl}, \mathrm{CYP} 2 \mathrm{C} 19 \text { genotype- } \\
\text { guided selection of } \mathrm{P}^{2} \mathrm{Y}_{12} \text { inhibitor therapy appeared to be an } \\
\text { effective strategy compared to standard therapy with clopidogrel. } \\
\text { Although the reduction in ischemic events was not statistically } \\
\text { significant at } 12 \text { months, the potential benefit of genotyped-guided } \\
\text { therapy appeared greatest within } 3 \text { months. }\end{array}$ \\
\hline
\end{tabular}

Abbreviations: $\mathrm{ACS}$, acute coronary syndrome; $\mathrm{CAD}$, coronary artery disease; $\mathrm{CV}$, cardiovascular, $\mathrm{Ml}$, myocardial infarction; $\mathrm{PCl}$, percutaneous coronary intervention; STEMI, ST segment elevation myocardial infarction.

received clopidogrel $150 \mathrm{mg} /$ day, PMs received doubledose clopidogrel plus cilostazol, and patients without a no function allele received standard-dose clopidogrel $(75 \mathrm{mg} /$ day). Patients randomized to conventional therapy (clopidogrel $75 \mathrm{mg} /$ day) had a higher risk of ischemic cardiovascular events at 6 months compared to genotype-guided 
therapy $(9.0 \%$ vs $2.7 \% ; \mathrm{p}=0.001)$, with no difference in bleeding risk.

More recently, three multicenter, randomized clinical trials evaluated the clinical utility of CYP2C19 genotypeguided antiplatelet therapy after PCI. The PHARMCLO (NCT03347435), ${ }^{39}$ POPular-Genetics (NCT01761786), ${ }^{40}$ and TAILOR-PCI (NCT01742117) ${ }^{41}$ trials offer important insight into the effectiveness and safety of a genotypeguided strategy. A comparison of the design and primary results of POPular-Genetics and TAILOR-PCI are summarized in Table 1.

\section{PHARMCLO}

The Pharmacogenetics of Clopidogrel in Acute Coronary Syndromes (PHARMCLO) trial evaluated the safety and effectiveness of genotype-guided antiplatelet therapy in 888 ACS patients across 12 centers in Italy. ${ }^{39}$ Patients were randomized to either standard or genotype-guided therapy, which used a treatment algorithm that considered CYP2C19*2, CYP2C19*17 and ABCB1 c.3435C $>$ T genotyping results; however, treatment was per provider discretion. Prasugrel or ticagrelor was prescribed in $41.1 \%$ of the standard-of-care arm and $50.2 \%$ of the genotypeguided arm; however, the proportion of CYP2C19 IMs and PMs prescribed alternative therapy was not reported. Genotype-guided therapy significantly reduced the risk of the primary endpoint of cardiovascular death, MI, stroke, or major bleeding compared to standard-of-care at 12 months (15.9\% vs $25.9 \%$; HR: 0.58 ; $95 \%$ CI: $0.43-0.78$; $\mathrm{p}<0.001)$. The genotype-guided arm had a lower risk of ischemic events $(13.0 \%$ vs $21.4 \%$; HR: 0.57 ; $95 \% \mathrm{CI}$ : $0.41-0.80 ; \mathrm{p}<0.001)$, and there was no significant difference in major bleeding between groups $(4.2 \%$ vs $6.8 \%$; $\mathrm{p}=0.10$ ). Although the trial was consistent with prior nonrandomized studies, the study was prematurely stopped due to lack of genotyping instrument certification and only enrolled $25 \%$ of the pre-specified sample size.

\section{POPular-Genetics}

The CYP2C19 Genotype-Guided Antiplatelet Therapy in ST-Segment Elevation Myocardial Infarction Patients Patient Outcome after Primary PCI (POPular Genetics) trial was a European, multicenter, randomized, openlabel, non-inferiority trial designed to determine whether CYP2C19 genotype-guided antiplatelet therapy selection in STEMI patients undergoing primary PCI could reduce bleeding risk while not increasing the risk of a thrombotic event (Table 1). ${ }^{40}$ Patients were randomized to receive standard therapy, defined as either ticagrelor or prasugrel per provider discretion, or $\mathrm{P}_{2} \mathrm{Y}_{12}$ inhibitor based on CYP2C19 genetic testing ( $\mathrm{n}=2488)$. Patients that carried one or two CYP2C19*2 or *3 alleles (IM/PMs) received ticagrelor or prasugrel, while non-carriers received clopidogrel $75 \mathrm{mg} /$ day.

The trial underwent a major protocol revision when the 2011 ESC MI guidelines recommended ticagrelor or prasugrel over clopidogrel therapy following PCI. ${ }^{48,49}$ The standard treatment group was changed from universal clopidogrel to ticagrelor or prasugrel, and the trial design to a non-inferiority design. These changes enhanced the rigor of the trial and made the results more applicable to contemporary practice. Prior to the protocol revision, only 179 patients had been enrolled; 2488 patients were enrolled after the revision. Individuals enrolled prior to the revision were excluded from the primary analysis.

The CYP2C19 genotype-guided strategy was noninferior to universal ticagrelor or prasugrel in occurrence of the primary combined outcome of death, MI, stent thrombosis, stroke, or major bleeding $(5.1 \%$ vs $5.9 \%$, respectively; absolute difference $-0.7 \%$; $95 \% \mathrm{CI}:-2.0$ $0.7 ; \mathrm{p}$ for non-inferiority $<0.001)$. There was a significant decrease in the primary bleeding outcome (major or minor bleeding) in the genotype-guided compared to the standard-treatment group (9.8 vs $12.5 \%$; HR: 0.78 ; $95 \% \mathrm{CI}$ : $0.61-0.98 ; \mathrm{p}=0.04$ ), which was driven by a reduction in minor bleeding ( $7.6 \%$ vs $10.5 \%$; HR: 0.72 ; $95 \%$ CI: $0.55-$ $0.94)$ since no difference in major bleeding was observed (2.3\% vs $2.3 \%$; HR: 0.97 ; 95\% CI: $0.58-1.63)$. The secondary outcome of death from vascular causes, MI, stent thrombosis, or stroke was not different between the genotype-guided and standard groups $(2.7 \%$ vs $3.3 \%$; HR: 0.83 ; $95 \%$ CI: $0.53-1.31$ ) and met the criteria for noninferiority. This illustrated that genotype-guided de-escalation of antiplatelet therapy in STEMI patients is a safe and effective strategy after PCI that does not increase thrombotic event risk.

\section{TAILOR-PCI}

The Tailored Antiplatelet Initiation to Lessen Outcomes due to Decreased Clopidogrel Response After Percutaneous Coronary Intervention (TAILOR-PCI) trial was a multicenter randomized, open-label, superiority trial of CYP2C19 genotype-guided antiplatelet therapy conducted in North American and Korea $(\mathrm{n}=5302)$. The trial was designed to determine whether identifying CYP2C19 no function alleles and altering $\mathrm{P} 2 \mathrm{Y}_{12}$ inhibitor therapy 
based on genotype results could reduce ischemic outcomes in patients undergoing PCI for an ACS or non-ACS indication compared to universal clopidogrel. ${ }^{41,51,52}$ In the genotype-guided group, CYP2C19*2 or *3 allele carriers received ticagrelor and wild-type individuals received clopidogrel $75 \mathrm{mg} /$ day. The conventional care arm received clopidogrel $75 \mathrm{mg} /$ day and was genotyped at the end of the trial period. The primary outcome was the composite of cardiovascular death, MI, stent thrombosis, stroke, or severe recurrent ischemia. The primary analysis, for which the study was powered, compared no function allele carriers in the prospective genotype-guided and conventional therapy arms. Although the complete trial results have not yet been published, the results of the primary analysis were recently reported. ${ }^{51,52}$

Overall, CYP2C19 no function allele carriers receiving ticagrelor exhibited a numerically lower risk of the primary MACE outcome compared to no function allele carriers receiving clopidogrel $(4.0 \%$ vs $5.9 \%$, respectively; HR: 0.66 ; 95\% CI: $0.43-1.02 ; \mathrm{p}=0.056$ ) however, the overall event rate was lower than anticipated and this difference was not statistically significant. In a post hoc analysis, no function allele carriers receiving ticagrelor had a lower risk of MACE within 3 months after PCI compared to clopidogrel (HR: $0.21 ; \mathrm{p}=0.001$ ). A sensitivity analysis evaluating multiple ischemic events per patient also demonstrated a lower ischemic event risk in the genotype-guided therapy group (HR: $0.60 ; 95 \% \mathrm{CI}$ : $0.41-0.89 ; \mathrm{p}=0.011)$. Bleeding rates were not different between groups. Taken together, these results demonstrate the potential benefits of a CYP2C19 genotype-guided strategy in ACS and non-ACS patients undergoing PCI; however, interpretation of the results is challenged by a lower than anticipated event rate, the lack of a significant difference in the primary outcome, and the pending availability of a publication detailing the trial's complete results.

\section{CYP2CI 9 Genotype, Clopidogrel and Clinical Outcomes: Neurology}

\section{Stroke and Transient Ischemic Attack}

The use of $\mathrm{P}_{2} \mathrm{Y}_{12}$ inhibitors to prevent atherothrombotic events is not limited to coronary artery disease (CAD) patients. In 2016, 5.5 million deaths worldwide were attributed to cerebrovascular disease. ${ }^{53}$ In patients experiencing an acute ischemic stroke or TIA, clopidogrel alone or in combination with aspirin has reduced the risk of recurrent stroke in multiple clinical trials. ${ }^{54,55}$ Accordingly, clinical practice guidelines recommend clopidogrel for treatment of acute ischemic stroke and TIA and secondary prevention of stroke. ${ }^{56}$ Ticlopidine, a first-generation $\mathrm{P}_{2} \mathrm{Y}_{12}$ inhibitor with an undesirable safety profile, is not impacted by CYP2C19 polymorphisms and is an alternative to clopidogrel for stroke prevention. ${ }^{57}$ Emerging clinical trial data suggest ticagrelor may offer clinical utility in the treatment and prevention of stroke, ${ }^{58}$ but additional studies are required to determine its role in stroke treatment. ${ }^{59}$ In contrast, prasugrel is contraindicated in patients with a history of TIA or stroke due to increased risk of major bleeding. ${ }^{59}$

The impact of interindividual variability in clopidogrel's antiplatelet effects on its clinical effectiveness in stroke patients has emerged as an important area of investigation. Multiple studies have examined the effects of CYP2C19 genotype on clopidogrel outcomes in the secondary prevention of stroke. A genetic substudy from the Secondary Prevention of Small Subcortical Strokes (SPS3) trial $(\mathrm{N}=522)$ observed a numerically higher risk of recurrent stroke in CYP2C19 IM/PMs compared with NM/UMs (OR: 1.81 ; 95\% CI: 0.76-4.30), but this association was not statistically significant. ${ }^{60}$ The association was statistically significant in a race-stratified analysis of white individuals (OR: 5.19; 95\% CI: 1.08-24.9). The overall SPS3 trial was terminated early due to an increased bleeding risk; however, this result was not explained by CYP2C19 genotype. An observational cohort study utilizing data from the Nanjing Stroke Registry included 625 consecutive patients with ischemic stroke who were genotyped for CYP2C19 variants and received clopidogrel. ${ }^{61}$ CYP2C19 IM/PMs demonstrated a higher risk of vascular events compared to those without a no function allele (HR: 2.16 ; 95\% CI: 1.31-3.56, $\mathrm{p}=0.003$ ).

The Clopidogrel in High-Risk Patients with Acute Nondisabling Cerebrovascular Events (CHANCE study) was a randomized, double-blind, placebo-controlled trial that evaluated the safety and efficacy of clopidogrel plus aspirin versus aspirin monotherapy in 5170 patients from 114 centers in China within 24 hrs after onset of minor stroke or high-risk TIA. ${ }^{62}$ Clopidogrel plus aspirin decreased the risk of recurrent stroke at 90 days and 1year, compared to aspirin monotherapy, without increasing major bleeding risk. ${ }^{54,62}$ In a genetic substudy ( $\left.n=2933\right)$, clopidogrel plus aspirin significantly reduced the risk of stroke at 90 days compared to aspirin monotherapy in patients without a no function allele $(6.7 \%$ vs $12.4 \%$, respectively; HR: $0.51 ; 95 \% \mathrm{CI}: 0.35-0.75 ; \mathrm{p}<0.01) .{ }^{63} \mathrm{In}$ contrast, no difference in risk was observed in patients 
with a no function allele $(9.4 \%$ vs $10.8 \%$; HR: 0.93 ; $95 \%$ CI: $0.69-1.26 ; \mathrm{p}=0.64)$. This analysis demonstrated that the reduction in stroke risk conferred by clopidogrel was driven by diminished efficacy in CYP2C19 IMs and PMs ( $p$ for interaction 0.02). A subsequent analysis demonstrated that these effects may be most pronounced in a subset of patients with impaired renal function (defined as estimated glomerular filtration rate (eGFR) $<75 \mathrm{~mL} / \mathrm{min} /$ $1.73 \mathrm{~m}^{2}$ ) and absent in patients with normal renal function. ${ }^{64}$

A meta-analysis of 15 studies $(\mathrm{n}=4762)$ further examined the effects of CYP2C19 no function alleles $(* 2, * 3$, and $* 8$ ) on clopidogrel outcomes following stroke or TIA. ${ }^{6}$ Two studies were post hoc analyses of randomized trials (including the CHANCE data described above) and 13 were cohort studies. The endpoints were stroke, composite vascular events, and any bleeding event. Individuals that carried a CYP2C19 no function allele exhibited a significantly higher risk of stroke (RR: 1.92; 95\% CI: 1.57-2.35; $\mathrm{p}<0.001$ ) and composite vascular events (RR: $1.51 ; 95 \%$ CI 1.10-2.06; $\mathrm{p}=0.01$ ) compared to noncarriers. However, there was no difference in bleeding events (RR: 0.89 ; 95\% CI: $0.58-1.35$; $\mathrm{p}=0.59$ ). The relative risk of stroke was higher in CYP2C19 PMs than IMs, demonstrating a gene-dose effect. Similar associations were observed in European and Asian patients. Although a significant association was not observed in patients of African ancestry, sample size was limited. Taken together, these retrospective genetic analyses demonstrate that CYP2C19 no function alleles diminish clopidogrel clinical effectiveness in the setting of acute ischemic stroke and TIA. However, prospective data characterizing the impact of a CYP2C19 genotype-guided antiplatelet therapy selection strategy on adverse neurological, vascular and bleeding outcomes in acute stroke and TIA patients are needed.

\section{Neurointerventional Procedures}

Clopidogrel therapy is also utilized to prevent thromboembolic events in the setting of carotid artery stenting (CAS), carotid endarterectomy (CEA), and intracranial aneurysm repair. ${ }^{65,66}$ Data evaluating associations between CYP2C19 variants and outcomes following cerebrovascular interventions are limited, but emerging. CYP2C19 metabolizer status was associated with clopidogrel's antiplatelet effects in 123 patients undergoing a percutaneous neurointervention procedure. ${ }^{67}$ Although no association between IM/PMs and ischemic outcomes was observed, UMs exhibited a higher risk of bleeding. A meta-analysis of 7 studies $(n=442)$ found that CYP2C19 $\mathrm{IM} / \mathrm{PMs}$ treated with clopidogrel had higher risk of thromboembolic complications post-neurointervention. ${ }^{68} \mathrm{~A}$ cohort study of patients who underwent CAS $(n=241)$ also observed that clopidogrel-treated patients carrying a CYP2C19 no function allele exhibited increased risk of ischemic events compared to non-carriers, suggesting that CYP2C19 genotype may impact prognosis post-CAS. ${ }^{69}$ In the setting of endovascular coiling with stenting, which is commonly used for intracranial aneurysm repair, ${ }^{70}$ clopidogrel-treated CYP2C19 IM/PMs exhibited an increased risk of ischemic events compared to non-carriers. ${ }^{71}$ These accumulating data demonstrate that CYP2C19 genotype is associated with outcomes in clopidogrel-treated patients following neurointerventional procedures; however, larger multicenter studies are needed to more confidently discern these risks and evaluate the effectiveness of alternative treatment strategies in CYP2C19 IM/PMs.

\section{Clinical Practice Guideline Recommendations}

Guideline recommendations surrounding the use of CYP2C19 genotype in the setting of stroke and neurointerventional procedures are limited due to the lack of prospective evidence. Currently, CPIC recommendations focus solely on the use of clopidogrel in the setting of coronary artery $\mathrm{PCI} ;{ }^{4}$ however, the DPWG extends its recommendations to acute stroke and TIA (CYP2C19 PMs: avoid clopidogrel; IMs: use alternative drug or double clopidogrel dose). ${ }^{26}$ The American Stroke Association secondary stroke prevention guideline notes that patients carrying a CYP2C19 no function allele can have reduced clopidogrel active metabolite levels and platelet inhibition, but does not provide recommendations for therapeutic alternatives or use of genetic testing to guide prescribing. ${ }^{72}$ Similarly, a 2018 European consensus statement does not address the use of CYP2C19 testing to guide clopidogrel prescribing in either acute stroke or secondary prevention. ${ }^{73}$

\section{Summary and Future Directions}

Recent randomized clinical trials and pragmatic studies have demonstrated that the use of CYP2C19 genetic testing to guide antiplatelet therapy selection following PCI can reduce MACE without increasing bleeding risk. Collectively, these data illustrate the safety and effectiveness of a genotype-guided strategy, suggesting that CYP2C19 genotype-guided antiplatelet therapy should be considered in high-risk PCI patients to improve patient outcomes, and will likely strengthen recommendations in the PCI clinical practice guidelines. In addition, 
because both CYP2C19 IMs and PMs treated with clopidogrel are at increased risk of atherothrombotic events, revising the FDA Boxed Warning for clopidogrel to include IM status also warrants consideration. However, several gaps in evidence remain that require further investigation.

Use of prasugrel or ticagrelor early after PCI for an ACS indication, when risk for atherothrombotic events is greatest, followed by de-escalation to clopidogrel for chronic therapy has become more common in practice as a strategy to reduce the early risk for major atherothrombotic events and long-term bleeding risk. $^{74,75}$ Although empiric (unguided) de-escalation to clopidogrel very early after ACS has been associated with an increased risk of recurrent atherothrombotic events, ${ }^{76}$ the Timing of Platelet Inhibition after ACS (TOPIC) randomized clinical trial demonstrated that de-escalation to clopidogrel 1 month after PCI significantly decreased risk for bleeding without increasing ischemic events compared to continued use of prasugrel or ticagrelor. ${ }^{77}$ The POPular Genetics trial demonstrated the safety and effectiveness of using rapid CYP2C19 genotype testing to selectively guide de-escalation to clopidogrel in STEMI patients without a no function allele. ${ }^{40}$ Similarly, the Testing Responsiveness To Platelet Inhibition On Chronic Antiplatelet Treatment For Acute Coronary Syndromes (TROPICAL-ACS) randomized trial, which utilized platelet function testing instead of genotype to guide deescalation from prasugrel to clopidogrel therapy in ACS patients 7 days after PCI and also showed no increase in MACE compared to universal prasugrel. ${ }^{50}$ Together, the POPular Genetics and TROPICAL-ACS trials demonstrate the clinical utility of a biomarker-guided de-escalation strategy during the early post-PCI period in ACS patients. However, an additional randomized trial investigating the effectiveness and safety of a CYP2C19 genotype-guided de-escalation strategy in ACS and non-ACS patients may be of value.

While the clinical benefit of genotype-guided antiplatelet therapy has been demonstrated in ACS patients post-PCI, the effects on clinical outcomes in several key subsets of the population are less clear. Notably, the clinical utility in African-Americans requires further study. Approximately $35 \%$ of Black populations carry a CYP2C19 no function allele. ${ }^{4}$ However, African-Americans constituted less than $2 \%$ of patients enrolled in the POPular Genetics and TAILOR-PCI clinical trials (Table 2). Despite a high prevalence of CAD, African-Americans represented approximately $5 \%$ of ACS clinical trial populations. ${ }^{78}$ As a consequence, potential racial differences in response to antiplatelet therapy and the effects of genotype-guided antiplatelet therapy on outcomes remain poorly understood. Research in real-world
Table 2 Study Population Comparison Across Major Trials of Genotype-Guided Antiplatelet Therapy

\begin{tabular}{|c|c|c|c|}
\hline $\begin{array}{l}\text { Population } \\
\text { Characteristics }\end{array}$ & IGNITE & $\begin{array}{l}\text { POPular } \\
\text { Genetics* }\end{array}$ & $\begin{array}{l}\text { TAILOR- } \\
\text { PCI* }\end{array}$ \\
\hline Age (mean) & 63 & 62 & 62 \\
\hline Female & $33 \%$ & $26 \%$ & $25 \%$ \\
\hline \multicolumn{4}{|l|}{ Race } \\
\hline Black & $16 \%$ & $<0.5 \%$ & $2 \%$ \\
\hline White & $78 \%$ & $94 \%$ & $47 \%$ \\
\hline Asian & $0.7 \%$ & $4 \%$ & $45 \%$ \\
\hline Other & $6 \%$ & $0.9 \%$ & $6 \%$ \\
\hline \multicolumn{4}{|l|}{ Indication for PCI } \\
\hline Stable/Elective & $31 \%$ & $0 \%^{\wedge}$ & $14 \%$ \\
\hline ACS & $67 \%$ & $100 \%$ & $86 \%$ \\
\hline STEMI & $19 \%$ & $100 \%$ & NR \\
\hline NSTEMI & $28 \%$ & $0 \%^{\wedge}$ & NR \\
\hline Unstable angina & $19 \%$ & $0 \%^{\wedge}$ & NR \\
\hline Current smoker & $30 \%$ & $46 \%$ & $25 \%$ \\
\hline $\begin{array}{l}\text { Body mass index } \\
\text { (mean) }\end{array}$ & 30 & 28 & NR \\
\hline Hypertension & $80 \%$ & $42 \%$ & $59 \%$ \\
\hline Diabetes & $38 \%$ & $12 \%$ & $28 \%$ \\
\hline Chronic kidney disease & $30 \% * *$ & $10 \% * *$ & $12 \% * *$ \\
\hline Prior MI & $26 \%$ & $8 \%$ & $12 \%$ \\
\hline Prior TIA/Stroke & $10 \%$ & $3 \%$ & $3 \%$ \\
\hline History of bleeding & $3 \%$ & $2 \%$ & NR \\
\hline On aspirin & $98 \%$ & $98 \%$ & $99 \%$ \\
\hline On oral anticoagulant & $8 \%$ & $4 \%$ & $0 \%^{\wedge}$ \\
\hline
\end{tabular}

Notes: *Data represents baseline characteristics in the genotype-guided arm of the study (TAILOR-PCI CYP2C19*2/*3 group): **Reported in baseline characteristics as eGFR $<60 \mathrm{~mL} / \mathrm{min}$ rather than CKD: ^Not eligible per study inclusion and exclusion criteria.

Abbreviation: NR, not reported.

patient populations, like the IGNITE Network, offer the potential to investigate these effects in more diverse settings. In addition to racial differences in CYP2C19 allele frequencies, Asian and Western countries exhibit population differences in body mass index, age at ACS presentation, and other factors that influence response to antithrombotic and antiplatelet drugs. ${ }^{79}$ Thus, future studies are also needed to compare the clinical utility of genotype-guided antiplatelet therapy across populations.

Furthermore, outcomes in PCI patients who require oral anticoagulation therapy remain limited (Table 2). Clopidogrel remains the primary $\mathrm{P}_{2} \mathrm{Y}_{12}$ inhibitor used in combination with anticoagulation therapy in patients with $\mathrm{CAD}$ and atrial fibrillation due to concerns for bleeding with prasugrel or ticagrelor. Recent clinical trials have found that, in patients treated with a direct oral anticoagulant (DOAC) like apixaban, single antiplatelet therapy (SAPT) 
with clopidogrel and no aspirin reduced the risk of bleeding and hospitalizations compared to DAPT. ${ }^{80}$ Thus, SAPT with clopidogrel plus a DOAC is becoming more common in practice. However, the risk of atherothrombotic events in CYP2C19 no function allele carriers receiving a DOAC and clopidogrel without aspirin is unknown. Future studies are needed to evaluate the impact of CYP2C19 genotype on clinical outcomes in patients receiving SAPT versus DAPT in combination with oral anticoagulation.

Lastly, it remains unclear whether additional clinical and genetic factors, beyond CYP2C19 no function alleles, can be used to predict atherothrombotic and bleeding event risk and more precisely inform antiplatelet therapy prescribing decisions. The recently reported ABCD-GENE (Age, Body Mass Index, Chronic Kidney Disease, Diabetes Mellitus, and CYP2C19 Genotyping) risk score was predictive of higher platelet reactivity and MACE risk in clopidogrel-treated patients. ${ }^{81}$ Although multifactorial risk prediction algorithms offer the potential to improve benefit-risk profiles in individual patients, further investigation is required.

In summary, a series of recent outcome-driven prospective studies further demonstrate the clinical utility of using CYP2C19 genotype testing to guide antiplatelet therapy prescribing in PCI patients. These effects appear most prominent in high-risk patients. Furthermore, accumulating data demonstrate that CYP2C19 genotype is associated with outcomes in clopidogrel-treated patients following stroke and neurointerventional procedures. These data parallel the increasingly common implementation of CYP2C19 genetic testing into clinical practice, will likely strengthen recommendations in PCI clinical practice guideline updates, and may ultimately be applicable in neurology clinical settings as additional evidence continues to emerge.

\section{Disclosure}

The authors report no conflicts of interest in this work.

\section{References}

1. Virani SS, Alonso A, Benjamin EJ, et al. Heart disease and stroke statistics-2020 update: a report from the american heart association. Circulation. 2020;141(9):e139-e596.

2. Levine GN, Bates ER, Bittl JA, et al. 2016 ACC/AHA guideline focused update on duration of dual antiplatelet therapy in patients with coronary artery disease. J Am Coll Cardiol. 2016;68(10):10821115. doi:10.1016/j.jacc.2016.03.513

3. Dayoub EJ, Seigerman M, Tuteja S, et al. Trends in platelet adenosine diphosphate P2Y12 receptor inhibitor use and adherence among antiplatelet-naive patients after percutaneous coronary intervention, 20082016. JAMA Intern Med. 2018;178(7):943-950. doi:10.1001/ jamainternmed.2018.0783
4. Scott SA, Sangkuhl K, Stein CM, et al. Clinical pharmacogenetics implementation consortium guidelines for CYP2C19 genotype and clopidogrel therapy: 2013 update. Clin Pharmacol Ther. 2013;94 (3):317-323. doi:10.1038/clpt.2013.105

5. Mega JL, Simon T, Collet JP, et al. Reduced-function CYP2C19 genotype and risk of adverse clinical outcomes among patients treated with clopidogrel predominantly for PCI: A meta-analysis. $J \mathrm{Am}$ Med Assoc. 2010;304(16):1821-1830. doi:10.1001/jama.2010.1543

6. Pan Y, Chen W, Xu Y, et al. Genetic polymorphisms and clopidogrel efficacy for acute ischemic stroke or transient ischemic attack. Circulation. 2017;135(1):21-33. doi:10.1161/ CIRCULATIONAHA.116.024913

7. Mega JL, Close SL, Wiviott SD, et al. Cytochrome P450 genetic polymorphisms and the response to prasugrel relationship to pharmacokinetic, pharmacodynamic, and clinical outcomes. Circulation. 2009;119 (19):2553-2560. doi:10.1161/CIRCULATIONAHA.109.851949

8. Wallentin L, James S, Storey RF, et al. Effect of CYP2C19 and ABCB1 single nucleotide polymorphisms on outcomes of treatment with ticagrelor versus clopidogrel for acute coronary syndromes: A genetic substudy of the PLATO trial. Lancet. 2010;376(9749):13201328. doi:10.1016/S0140-6736(10)61274-3

9. Klein MD, Williams AK, Lee CR, Stouffer GA. Clinical utility of CYP2C19 genotyping to guide antiplatelet therapy in patients with an acute coronary syndrome or undergoing percutaneous coronary intervention. Arterioscler Thromb Vasc Biol. 2019;39(4):647-652. doi:10.1161/ATVBAHA.118.311963

10. Klein MD, Lee CR, Stouffer GA. Clinical outcomes of CYP2C19 genotype-guided antiplatelet therapy: existing evidence and future directions. Pharmacogenomics. 2018;19(13):1039-1046. doi:10.2217/pgs-2018-0072

11. Empey PE, Stevenson JM, Tuteja S, et al. Multisite investigation of strategies for the implementation of CYP2C19 genotype-guided antiplatelet therapy. Clin Pharmacol Ther. 2018;104(4):664-674. doi:10.1002/cpt.1006

12. Zhou Y, Ingelman-Sundberg M, Lauschke V. Worldwide distribution of cytochrome P450 alleles: a meta-analysis of population-scale sequencing projects. Clin Pharmacol Ther. 2017;102(4):688-700. doi:10.1002/cpt.690

13. Fricke-Galindo I, Céspedes-Garro C, Rodrigues-Soares F, et al. Interethnic variation of CYP2C19 alleles, "predicted" phenotypes and "measured" metabolic phenotypes across world populations. Pharmacogenomics J. 2016;16(2):113-123. doi:10.1038/tpj.2015.70

14. PharmVar.org. Pharmacogene variation consortium; [updated Apr 13, 2020; cited Apr 5, 2020]. Available from: https://www.pharmvar.org/ gene/CYP2C19. Accessed April 5, 2020.

15. Caudle KE, Dunnenberger HM, Freimuth RR, et al. Standardizing terms for clinical pharmacogenetic test results: consensus terms from the Clinical Pharmacogenetics Implementation Consortium (CPIC). Genet Med. 2017;19(2):215-223. doi:10.1038/gim.2016.87

16. Sibbing D, Koch W, Gebhard D, et al. Cytochrome 2c19*17 allelic variant, platelet aggregation, bleeding events, and stent thrombosis in clopidogrel-treated patients with coronary stent placement. Circulation. 2010;121(4):512-518. doi:10.1161/CIRCULATIONA HA. 109.885194

17. Li Y, Tang HL, Hu YF, Xie HG. The gain-of-function variant allele CYP2C19*17: A double-edged sword between thrombosis and bleeding in clopidogrel-treated patients. J Thromb Haemost. 2012;10 (2):199-206. doi:10.1111/j.1538-7836.2011.04570.x

18. Tiroch KA, Sibbing D, Koch W, et al. Protective effect of the CYP2C19*17 polymorphism with increased activation of clopidogrel on cardiovascular events. Am Heart J. 2010;160(3):506-512. doi:10.1016/j.ahj.2010.06.039

19. Lewis JP, Stephens SH, Horenstein RB, et al. The CYP2C19*17 variant is not independently associated with clopidogrel response. $J$ Thromb Haemost. 2013;11(9):1640-1646. doi:10.1111/jth.12342 
20. Lewis JP, Backman JD, Reny J-L. et al. Pharmacogenomic polygenic response score predicts ischemic events and cardiovascular mortality in clopidogrel-treated patients. Eur Hear $J$ Cardiovasc Pharmacother. 2020;6(4):203-210. doi:10.1093/ehjcvp/pvz045

21. Sorich MJ, Vitry A, Ward MB, Horowitz JD, Mckinnon RA. Prasugrel vs. clopidogrel for cytochrome P450 2C19-genotyped subgroups: integration of the TRITON-TIMI 38 trial data. J Thromb Haemost. 2010;8 (8):1678-1684. doi:10.1111/j.1538-7836.2010.03923.x

22. Varenhorst C, Eriksson N, Johansson $\AA$, et al. Effect of genetic variations on ticagrelor plasma levels and clinical outcomes. Eur Heart J. 2015;36(29):1901-1912a. doi:10.1093/eurheartj/ehv116

23. Holmberg MT, Tornio A, Paile-Hyvärinen M, et al. CYP3A4*22 impairs the elimination of ticagrelor, but has no significant effect on the bioactivation of clopidogrel or prasugrel. Clin Pharmacol Ther. 2019;105(2):448-457. doi:10.1002/cpt.1177

24. Holmes DR, Dehmer GJ, Kaul S, Leifer D, O'Gara PT, Stein CM. ACCF/AHA clopidogrel clinical alert: approaches to the FDA "boxed warning": A report of the American college of cardiology foundation task force on clinical expert consensus documents and the American heart association. $J$ Am Coll Cardiol. 2010;56(4):321-341. doi:10.1016/j.jacc.2010.05.013

25. Food and Drug Administration. Reduced effectiveness of plavix (clopidogrel) in patients who are poor metabolizers of the drug; safety announcement; 2010 Mar. Available from: https://www.fda. gov/drugs/postmarket-drug-safety-information-patients-and-provi ders/fda-drug-safety-communication-reduced-effectiveness-plavixclopidogrel-patients-who-are-poor. Accessed January 17, 2020.

26. Annotation of DPWG guideline for clopidogrel and CYP2C19. PharmGKB; [updated Feb 10, 2020; cited Apr 23, 2020]. Available from: https://www.pharmgkb.org/guidelineAnnotation/PA166104956. Accessed January 17, 2020.

27. Levine GN, Bates ER, Blankenship JC, et al. ACCF/AHA/SCAI guideline for percutaneous coronary intervention a report of the American College of Cardiology Foundation/American Heart association task force on practice guidelines and the society for cardiovascular angiography and interventions. Circulation. 2011;124 (23):574-651.

28. Valgimigli M, Bueno H, Byrne RA, et al. 2017 ESC focused update on dual antiplatelet therapy in coronary artery disease developed in collaboration with EACTS. Eur J Cardio-Thoracic Surg. 2018;53 (1):34-78. doi:10.1093/ejcts/ezx334

29. Knuuti J, Wijns W, Achenbach S, et al. 2019 ESC guidelines for the diagnosis and management of chronic coronary syndromes. Eur Heart J. 2020;41(3):407-477.

30. Sibbing D, Aradi D, Alexopoulos D, et al. Updated expert consensus statement on platelet function and genetic testing for guiding P2Y12 Receptor inhibitor treatment in percutaneous coronary intervention. JACC Cardiovasc Interv. 2019;12(16):1521-1537. doi:10.1016/j. jcin.2019.03.034

31. Roberts JD, Wells GA, Le May MR, et al. Point-of-care genetic testing for personalisation of antiplatelet treatment (RAPID GENE): A prospective, randomised, proof-of-concept trial. Lancet. 2012;379 (9827):1705-1711. doi:10.1016/S0140-6736(12)60161-5

32. So DYF, Wells GA, McPherson R, et al. A prospective randomized evaluation of a pharmacogenomic approach to antiplatelet therapy among patients with ST-elevation myocardial infarction: the RAPID STEMI study. Pharmacogenomics J. 2016;16(1):71-78. doi:10.1038/ tpj.2015.17

33. Koltowski L, Tomaniak M, Aradi D, et al. Optimal antiplatelet pharmacotherapy guided by bedSIDE genetic or functional testing in elective PCI patients: A pilot study: ONSIDE TEST pilot. Cardiol J. 2017;24(3):284-292. doi:10.5603/CJ.a2017.0026

34. Tam CC, Kwok J, Wong A, et al. Genotyping-guided approach versus the conventional approach in selection of oral P2Y12 receptor blockers in Chinese patients suffering from acute coronary syndrome. $J$ Int Med Res. 2017;45(1):134-146. doi:10.1177/0300060516677190
35. Tuteja S, Glick H, Matthai W, et al. Prospective CYP2C19 genotyping to guide antiplatelet therapy following percutaneous coronary intervention: a pragmatic randomized clinical trial. Circ Genomic Precis Med. 2020;13(1):e002640. doi:10.1161/CIRCGEN.119.002640

36. Cavallari LH, Lee CR, Beitelshees AL, et al. Multisite investigation of outcomes with implementation of CYP2C19 genotype-guided antiplatelet therapy after percutaneous coronary intervention. JACC Cardiovasc Interv. 2018;11(2):181-191. doi:10.1016/j.jcin.2017.07.022

37. Hulot JS, Chevalier B, Belle L, et al. Routine CYP2C19 genotyping to adjust thienopyridine treatment after primary PCI for STEMI: results of the GIANT study. JACC Cardiovasc Interv. 2020;13 (5):621-630. doi:10.1016/j.jcin.2020.01.219

38. Martin J, Williams AK, Klein MD, et al. Frequency and clinical outcomes of CYP2C19 genotype-guided escalation and de-escalation of antiplatelet therapy in a real-world clinical setting. Genet Med. 2020;22(1):160-169. doi:10.1038/s41436-019-0611-1

39. Notarangelo FM, Maglietta G, Bevilacqua P, et al. Pharmacogenomic approach to selecting antiplatelet therapy in patients with acute coronary syndromes: the PHARMCLO Trial. $\mathrm{J}$ Am Coll Cardiol. 2018;71(17):1869-1877. doi:10.1016/j.jacc.2018.02.029

40. Claassens DMF, Vos GJA, Bergmeijer TO, et al. A genotype-guided strategy for oral P2Y12 inhibitors in primary PCI. $N$ Engl J Med. 2019;381(17):1621-1631. doi:10.1056/NEJMoa1907096

41. Pereira NL, Rihal CS, So DYF, et al. Clopidogrel pharmacogenetics state-of-the-art review and the TAILOR-PCI study. Circ Cardiovasc Interv. 2019;12:4. doi:10.1161/CIRCINTERVENTIONS.119.0 07811

42. Shen DL, Wang B, Bai J, et al. Clinical value of CYP2C19 genetic testing for guiding the antiplatelet therapy in a Chinese population. J Cardiovasc Pharmacol. 2016;67(3):232-236. doi:10.1097/ FJC.0000000000000337

43. Sánchez-Ramos J, Dávila-Fajardo CL, Toledo Frías P, et al. Results of genotype-guided antiplatelet therapy in patients who undergone percutaneous coronary intervention with stent. Int $J$ Cardiol. 2016;225:289-295. doi:10.1016/j.ijcard.2016.09.088

44. Deiman BALM, Tonino PAL, Kouhestani K, et al. Reduced number of cardiovascular events and increased cost-effectiveness by genotype-guided antiplatelet therapy in patients undergoing percutaneous coronary interventions in the Netherlands. Netherlands Hear J. 2016;24(10):589-599. doi:10.1007/s12471-016-0873-z

45. Lee CR, Sriramoju VB, Cervantes A, et al. Clinical outcomes and sustainability of using CYP2C19 genotype-guided antiplatelet therapy after percutaneous coronary intervention. Circ Genomic Precis Med. 2018;11(4):e002069.

46. Williams AK, Klein MD, Martin J, et al. CYP2C19 genotype-guided antiplatelet therapy and 30-day outcomes after percutaneous coronary intervention. Circ Genomic Precis Med. 2019;12(2):e002441. doi:10.1161/CIRCGEN.119.002441

47. Xie X, Ma YT, Yang YN, et al. Personalized antiplatelet therapy according to CYP2C19 genotype after percutaneous coronary intervention: A randomized control trial. Int J Cardiol. 2013;168 (4):3736-3740. doi:10.1016/j.ijcard.2013.06.014

48. Hamm CW, Bassand JP, Agewall S, et al. Israrci STsegment yükselmesi belirtileri göstermeyen hastalarda Akut KoronerSendromlarin (AKS) tedavi kilavuzlari. Turk Kardiyol Dern Ars. 2011;39(SUPP-3):73-128.

49. Ibanez B, James S, Agewall S, et al. 2017 ESC guidelines for the management of acute myocardial infarction in patients presenting with ST-segment elevation. Eur Heart J. 2018;39(2):119-177.

50. Sibbing D, Aradi D, Jacobshagen C, et al. Guided de-escalation of antiplatelet treatment in patients with acute coronary syndrome undergoing percutaneous coronary intervention (TROPICALACS): a randomised, open-label, multicentre trial. Lancet. 2017;390(10104):1747-1757. doi:10.1016/S0140-6736(17)321 $55-4$ 
51. Pereira NL. TAILOR PCI: tailored antiplatelet initiation to lessen outcomes due to decreased clopidogrel response after percutaneous coronary intervention. Proceedings of American College of Cardiology Virtual Annual Scientific Session Together With World Congress of Cardiology (ACC 2020/WCC), March 28, 2020. Available from: https://www.acc.org/latest-in-cardiology/clinical-trials/2020/03/26/19/ 53/tailor-pci\#references-for-article. Accessed April 7, 2020.

52. TAILOR-PCI: genotype-guided antiplatelet therapy post PCI Misses Mark. American College of Cardiology. Available from: https://www. acc.org/latest-in-cardiology/articles/2020/03/24/16/41/sat-9am-tailorpci-clinical-implementation-clopidogrel-pharmacogenetics-acc-2020 . Accessed April 7, 2020.

53. Benjamin EJ, Muntner P, Alonso A, et al. Heart disease and stroke statistics-2019 update: a report from the American Heart Association. Circulation. 2019;139(10):e56e528.

54. Wang Y, Pan Y, Zhao X, et al. Clopidogrel with aspirin in acute minor stroke or transient ischemic attack (CHANCE) trial one-year outcomes. Circulation. 2015;132(1):40-46. doi:10.1161/CIRCULATIONAHA. 114.014791

55. Johnston SC, Easton JD, Farrant M, et al. Clopidogrel and aspirin in acute ischemic stroke and high-risk TIA. $N$ Engl J Med. 2018;379 (3):215-225. doi:10.1056/NEJMoa1800410

56. Powers WJ, Rabinstein AA, Ackerson T, et al. Guidelines for the early management of patients with acute ischemic stroke: 2019 update to the 2018 guidelines for the early management of acute ischemic stroke: a guideline for healthcare professionals from the American Heart Association/American Stroke. Stroke. 2019;50(12) e344e418. doi:10.1161/STR.0000000000000211

57. Maeda A, Ando H, Asai T, et al. Differential impacts of CYP2C19 gene polymorphisms on the antiplatelet effects of clopidogrel and ticlopidine. Clin Pharmacol Ther. 2011;89(2):229-233. doi:10.1038/ clpt.2010.268

58. Johnston SC, Amarenco P, Albers GW, et al. Ticagrelor versus aspirin in acute stroke or transient ischemic attack. $N$ Engl J Med. 2016;375 (1):35-43. doi:10.1056/NEJMoa1603060

59. Hackam DG, Spence JD. Antiplatelet therapy in ischemic stroke and transient ischemic attack. Stroke. 2019;50(3):773-778. doi:10.1161/ STROKEAHA.118.023954

60. McDonough CW, McClure LA, Mitchell BD, et al. CYP2C19 metabolizer status and clopidogrel efficacy in the Secondary Prevention of Small Subcortical Strokes (SPS3) study. J Am Heart Assoc. 2015;4 (6):e001652. doi:10.1161/JAHA.114.001652

61. Sun W, Li Y, Li J, et al. Variant recurrent risk among stroke patients with different CYP2C19 phenotypes and treated with clopidogrel. Platelets. 2015;26(6):558-562. doi:10.3109/09537104.2014.953044

62. Wang Y, Wang Y, Zhao X, et al. Clopidogrel with aspirin in acute minor stroke or transient ischemic attack. N Engl J Med. 2013;369 (1):11-19. doi:10.1056/NEJMoa1215340

63. Wang Y, Zhao X, Lin J, et al. Association between CYP2C19 loss-offunction allele status and efficacy of clopidogrel for risk reduction among patients with minor stroke or transient ischemic attack. $J \mathrm{Am}$ Med Assoc. 2016;316(1):70-78. doi:10.1001/jama.2016.8662

64. Wu Y, Zhou Y, Pan Y, et al. Impact of CYP2C19 polymorphism in prognosis of minor stroke or TIA patients with declined eGFR on dual antiplatelet therapy: CHANCE substudy. Pharmacogenomics J. 2018;18(6):713-720. doi:10.1038/s41397-018-0018-4

65. Naylor AR, Ricco JB, de Borst GJ, et al. Editor's choice management of atherosclerotic carotid and vertebral artery disease: 2017 clinical practice guidelines of the European Society for Vascular Surgery (ESVS). Eur J Vasc Endovasc Surg. 2018;55(1):3-81. doi:10.1016/j.ejvs.2017.06.021

66. McKevitt FM, Randall MS, Cleveland TJ, Gaines PA, Tan KT, Venables GS. The benefits of combined anti-platelet treatment in carotid artery stenting. Eur J Vasc Endovasc Surg. 2005;29(5):522527. doi:10.1016/j.ejvs.2005.01.012
67. Saiz-Rodríguez M, Romero-Palacián D, Villalobos-Vilda C, et al. Influence of CYP2C19 phenotype on the effect of clopidogrel in patients undergoing a percutaneous neurointervention procedure. Clin Pharmacol Ther. 2019;105(3):661-671. doi:10.1002/cpt.1067

68. Duconge J, Hernandez-Suarez DF. Potential usefulness of clopidogrel pharmacogenetics in ce rebral endovascular procedures and carotid artery stenting. Curr Clin Pharmacol. 2017;12(1):11. doi:10.2174/ 1574884712666170227154654

69. Zhu WY, Zhao T, Xiong XY, et al. Association of CYP2C19 polymorphisms with the clinical efficacy of clopidogrel therapy in patients undergoing carotid artery stenting in Asia. Sci Rep. 2016;6.

70. Jeong HW, Seo JH, Kim ST, Jung CK, Suh S. Clinical practice guideline for the management of intracranial aneurysms. Neurointervention. 2014;9(2):63. doi:10.5469/neuroint.2014.9.2.63

71. Ge H, Lv X, Ren H, et al. Influence of CYP2C19 genetic polymorphisms on clinical outcomes of intracranial aneurysms treated with stent-assisted coiling. J Neurointerv Surg. 2017;9(10):958-962. doi:10.1136/neurintsurg-2016-012635

72. Kernan WN, Ovbiagele B, Black HR, et al. Guidelines for the prevention of stroke in patients with stroke and transient ischemic attack: A guideline for healthcare professionals from the American Heart Association/American Stroke Association. Stroke. 2014;45(7):21602236. doi:10.1161/STR.0000000000000024

73. Ahmed N, Audebert H, Turc G, et al. Consensus statements and recommendations from the ESO-Karolinska stroke update conference, Stockholm 11-13 November 2018. Eur Stroke J. 2019;4 (4):307-317. doi:10.1177/2396987319863606

74. Angiolillo DJ, Rollini F, Storey RF, et al. International expert consensus on switching platelet P2Y12 receptor-inhibiting therapies. Circulation. 2017;136(20):1955-1975. doi:10.1161/ CIRCULATIONAHA.117.031164

75. Cavallari LH, Lee CR. A case for genotype-guided de-escalation of antiplatelet therapy after percutaneous coronary angioplasty. Future Cardiol. 2019;15(4):251-254. doi:10.2217/fca-2019-0017

76. De Luca L, D’Ascenzo F, Musumeci G, et al. Incidence and outcome of switching of oral platelet $\mathrm{P} 2 \mathrm{Y} 12$ receptor inhibitors in patients with acute coronary syndromes undergoing percutaneous coronary intervention: the SCOPE registry. EuroIntervention. 2017;13(4):459466. doi:10.4244/EIJ-D-17-00092

77. Cuisset T, Deharo P, Quilici J, et al. Benefit of switching dual antiplatelet therapy after acute coronary syndrome: the TOPIC (timing of platelet inhibition after acute coronary syndrome) randomized study. Eur Heart J. 2017;38(41):3070-3078. doi:10.1093/eurheartj/ehx175

78. Tahhan AS, Vaduganathan M, Greene SJ, et al. Enrollment of older patients, women, and racial/ethnic minority groups in contemporary acute coronary syndrome clinical trials. JAMA Cardiol. 2020;5:714. doi:10.1001/jamacardio.2020.0359.

79. Saito Y, Kobayashi Y, Tanabe K, Ikari Y. Antithrombotic therapy after percutaneous coronary intervention from the Japanese perspective. Cardiovasc Interv Ther. 2020;35(1):19-29. doi:10.1007/s12928019-00633-6

80. Lopes RD, Heizer G, Aronson R, et al. Antithrombotic therapy after acute coronary syndrome or PCI in atrial fibrillation. $N$ Engl J Med. 2019;380(16):1509-1524. doi:10.1056/NEJMoa1817083

81. Angiolillo DJ, Capodanno D, Danchin N, et al. Derivation, validation, and prognostic utility of a prediction rule for nonresponse to clopidogrel: the ABCD-GENE score. JACC Cardiovasc Interv. 2020;13(5):606-617. doi:10.1016/j.jcin.2020.01.226 


\section{Publish your work in this journal}

Pharmacogenomics and Personalized Medicine is an international, peer-reviewed, open access journal characterizing the influence of genotype on pharmacology leading to the development of personalized treatment programs and individualized drug selection for improved safety, efficacy and sustainability. This journal is indexed

on the American Chemical Society's Chemical Abstracts Service (CAS). The manuscript management system is completely online and includes a very quick and fair peer-review system, which is all easy to use. Visit http://www.dovepress.com/testimonials.php to read real quotes from published authors. 